\section{INTRODUCTION TO A DISCUSSION}

\section{INTRA-UTERINE DEATH:}

ITs

PATHOLOGY AND PREVENTIVE TREATMENT.

Read in the Section of Obstetric Medicine at the Annual Meeting of the British Medical Association, held in Glasgow,

August, 1888.

By Professor SIMPSON, Edinburgh.

Tre topic which has been proposed for discussion to-day has recently been expounded with great ability and fulness of illustration by Dr. Priestley. When I remind you that Dr. Priestley tells us he found it impossible to treat The Pathology of Intra-uterine Death exhaustively in the Lumleian Lectures, you will see that I must not attempt to do more than outline the subject now, by way of indicating the points on which we may hope to gain information from the wisdom and experience of the obstetricians here assembled.

\section{PATHOLOGY.}

Let me group the causes of intra-uterine death under the three rubrics of, 1, Fotal ; 2, Maternal ; 3, Placental. I do not overlook the well-known circumstance that conditions of disease or debility on the part of the male parent are often the obvious source of the pregnancy disaster. But the paternal influence, as a rule, produces its mischievous effect by the development of morbid processes in the fœtus, in its mother, or in the placenta which forms the channel of communication between the two.

1. Fotal Causes of Intra-Uterine Death.-As regards the causes of death in utero on the part of the fœtus itself, we note that it may die, first, of some acute disease; secondly, of some chronic afiection: thirdly, from some accident.

First, we have occasional illustrations of the death of the intra-uterine fotus from . Icute Disease during certain epidemics, when the mother is affected with a zymotic poison, and passes through the attack without aborting, but casts a dead fœtus with healthy appendages a few weeks later. We may have a woman seven months pregnant, for example, passing through an attack of modified small-pox, and three weeks after the fever has subsided she may give birth to a dead fotus with pustules all over the body, and the placenta giving no evidence of pathological disturbance. Such cases we may any of us have seen, when probably the fotus died of the pyrexia. In this category we may class the cases where the fotus has been the subject of extensive inflammation, as in those instances where not only effusion into the abdominal carity, but the presence of flakes of lymph on the liver, sploen and intestinal coils gives evidence of active peritonitis.

Secondly, in those women who have a succession of infants dying in utero, we have far more frequently to do with cases where the fœetus is the subject of some Chronic Affection. The syphilitic affections of the viscera, for instance, would be enough of themselves to prove fatal to the foetus, apart from the morbid changes in the placenta, which are, however, more commonly the cause of death; and in this group we must place some of the dead infants that are born dropsical, scleremic, or the subjects of malarial or other affections of the spleen, liver, or kidneys.

Thirdly, the death of the fœetus may be Accidental-the result of some traumatism, or it may be brought about from some unusual condition of the umbilical cord, whether from the much debated and doubtful exaggeration of its torsion, or from its more clearly established pathological convolutions and knot-formations. Thus we may see a dead foetus with the cord coiled simultaneously round the neck and the right thigh, in such a fashion that the struggles of the infant set up by interference with the funic circulation must necessarily have increased the difficulty and brought about the death; and in cases where twins are developed in a common sac, the cords may be so entangled that in one the circulation is completely arrested, and the child to which it is adherent dies.

2. Maternal Causes of Intra-Uterine Death.-The conditions on the part of the mother that lead to death of the foetus are somotimes: First, general, when the woman is the subject of some constitutional disorder, or of disease in some important organ ; or, secondly, local, when the fault is in the uterus itself or its immediate surroundings.

First, of Constitutional diseases affecting a pregnant woman, and liable to cause interruption of her gestation, we may take note of the zymotic affections, which may produce their fatal effect either by their pyrexial intensity, or by stimulating the uterus to cast its contents untimeously, or by the tendency to hiemorrhage resulting from the changes in the blood; all this, it may be, before there is time for the foetus itself to give evidence of having been infected with the poison. The same results are seen in acute diseases, such as pneumonia, acute yellow atrophy of the liver, septicæmia, erysipelas, metallic poisonings, etc. Where a woman has a series of miscarriages, however, we are more likely to have to do with one who is the subject of some cardiac lesion which becomes aggravated during pregnancy: or she suffers from anæmia or leukgmia. In some rare cases the urine is diabetic; not so seldom it contains albumen. Death of the foetus may here be due to imperfect nutrition or respiration from the morbid condition of the blood ; which may also, however, tend to set up premature uterine activity, or, more frequently still, give a proclivity to uterine hæmorrhage.

Secondly, as regards the Local maternal causes of intra-uterine death, we note that, whilst displacements and chronic inflammations of the uterus are to blame for many cases of habitual abortion in the early months, these do not manifest their pernicious influence so commonly after the foetus has come to its fuller development. Only in some of the cases of chronic endometritis, where the ovum has escaped the risks of the imperfect formation or dangerous implantation of the placenta and of the decidual hæmorrhages to which such patients are so prone, the fœtus may suffer and languish and even die when the catarrhal condition becomes established, which is associated with the debilitating drain commonly described as hydrorrhœa gravidarum.

3. Placental Causes of Intra-uterine Death. - The greatest number of cases of intra-uterine death by far are traceable to morbid conditions of the placenta. This is just what we might expect from a consideration of the functional importance of this organ. As regards the foetus itself, we may meet with individual cases where the brain and spinal cord are wanting, where the liver is ductless, the gullet or intestines occluded, or the kidneys supplanted by two cystic masses, without any impairment of its intra-uterine vitality; and the acardiac monster lives on till the close of pregnancy because its circulation is kept up by the effort of its large-hearted twin brother. In every one of these conditions, alimentation, oxygenation and elimination of waste products all go on through the medium of the placenta, and the defect or degeneration in the foetal organ only comes into prominence when there is a call for its functional activity after the work of the placenta is done. As regards the mother, she may be reduced to the last degree of weakness, as we may see in some cases of phthisis, and yet the parasite in her womb will live and thrive at her expense if only the medium of its communication with her system remain unaffected.

In taking up the placental causes of death we may leave out of our discussion to-dny the cases where the placenta has been implanted in dangerous zones, or presents peculiarities in its size or mode of development, and fix our attention on the morbid changes in its structure, whether these be, first, neoplastic; secondly, nutritional; or thirdly, apoplectic.

First, Neoplastic degenerations of the placenta may be found either in the fotal or maternal elements of it, the new growth taking the place of the normal structures or interfering with their functional activity. In the myxomatous placenta we have an instance of degeneration of tissues belonging to the ovum. This kind of mal-derelopment is much more familiar to us in the cases where it sets in at an early stage of pregnancy, and affects the whole chorionic surface, so that all the villi become the seat of hydatigenous change, and the pregnancy ends in the production of a vesicular mole; but the same process may set in at a later stnge among the growing placental villi, with the result that many of the villi become transformed into cystic masses pressing upon the healthier structures, and according to their extent impairing or alolishing the life-sustaining function of the whole placenta. Growths of various kinds bit of somewhat doubtful character have sometimes been described as seated in the decidual portion of the placenta. Perhaps we should reckon amongst these the 
gummata that have been found by various observers in the uterine portion of the placenta in women who are markedly syphilitic, and that consist of patches of fibrous and granulation tissue scattered through the cotyledons. Decidual neoplasms, however, are usually localised and too limited in extent to affect deeply the integrity of the organ.

Secondly, the Nutritional changes in the placenta include the inflammations and degenerations of tissue, which are beyond all question the most common cause of the impairment of its functions, and so of interference with the vigour or vitality of the infant. They are the pathological processes to which it is must needful to direct our attention, and in regard to which important aid will be given by clearer views as to the structure and development of the normal placenta. Until, for instance, anatomists have succeeded in determining for us whether the epithelial mantle of the active placental villi takes its origin from the cliorion or from the decidua, we remain uncertain whether to seek for the explanation of its pathological changes in causes on the part of the ovum or the uterus. Referring it provisionally to the chorion we may note that the pathological processes in (1) the Fotal portions of the placenta usually affect all the elements of a villus, but can sometimes be traced primarily or principally to changes $(a)$ in the Vessels, $(b)$ in the Yarenchyma, (c) in the Epithelial investment.

(a) Researches into the degeneratire processes in syphylitic placenta have made it very plain that the coats of the placental Blood-vessels undergo in many cases a degree of thickening and hypertrophy that way lead to obliteration of their canals. Where such changes aftect the capillaries in the rilli, morbid processes are often found reaching back into the larger vessels, and occasionally it is in the umbilical cord itself that the intima or adventitia are more distinctly atheromatous or thickened.

(b) In other instances the occlusion of the vessels is due not so much to thickening of their walls as to compression caused by morbid processes going on in the surrounding Parenchyma. Instead of remaining as a layer of transparent mucoid tissue sustaining the capillaries and allowing them to lie close to the epithelial surface bathed in the maternal blood, the substance of the villus becomes swollen and dim, sometimes simply in a state of great cedema, sometimes crowded with granulated cells. The enlarged structures fill up the lacunar spaces and obstruct the maternal blood-flow in the affected cotyledon, whilst the compression of the foetal blood-vessels may lead to congestion in the neighbouring territories. The irritative process that at first causes hypertrophy of the chorio-placental parenchyma may produce a secondary stage of fibrous degeneration when the tissue becomes dense and cirrhotic and atrophy sets in in the morbid areas.

(c) It is in their Epithelial covering, however, that we should look for the most important of the pathological processes in the placental villi. Whilst the walls of the capillaries and their surrounding parenchyma may have a mechanical influence in determining the flux and reflux between mother and foetus, it is to the epithelial cells that invest them that the more vital function must belong of elaborating from the maternal blood the pabulum necessary for transmission to the foetus, or of extracting from the foctal blood the waste products to be thrown into the mother's circulation. It is in this element of the placental villi, accordingly, that we find the most constant changes when the function of the placenta is interrupted. When the fotus dies from any nonplacental cause, the first and most advanced retrogressive change in the placenta is fatty degeneration of the villous epi. '.'ium. Whenerer damage is done to the placenta, as in cases of bloodextrarasation, again the epithelial cells degenerate. When the placenta is odematous, and when it is cirrhotic, whaterer changes affect the vessels or the parenchyma, we constantly see that the epithelial covering shares in the morbid process. Sometimes it is in a state of swelling and hyperplasia, its cells enlarging, multiplying, and becoming cloudy, or its elements become fattily degenerated and disintegrated, and according as the process is more or less widely diffused throughout the cotyledons is the degree of danger to the life of the foetus. The agent which can be most distinctly recognised as active in the production of these villous diseases and degenerations is the syphilitic rirus, and where this has been introduced into the orum of a healthy woman by tainted semen it is in these fotal portions of the placenta that we have the primary and principal manifestations of the mischief. But probably the degenerative processes have at times another origin, as we may see the cedematous or fatty placenta associated with drorsical states of the foctus or morbid conditions of the maternal blood, where no history of syphilitic infection can be
obtained, and no pathological changes of a distinctively syphilitic character can be observed.

(2) The Maternal portion of the placentu may be the seat of inflammatory, hypertrophic, and degenerative clanges. The irritative process may affect chiefly the uterine or excernal parietal layer of the placenta, leading to induration of the surface such as renders the separation difficult in the third stage of labour, and gives rise to the varieties of adherent placenta which cannot be thrown off by an active uterus. The cases with which we have at present to do are those where the trabecular and boundary layers are implicated as well, and the decidual tissue through which the maternal blood circulates and in which the foetal villi are embedded are the seat of change. Here processes parallel to those seen in the foetal elements have been observed. Sometimes the tissue is œdematous, soft, and swollen, with the decidual cells enlarged and dim and hyperplastic, the whole placenta being enlarged and pale. In other cases the cells are found in a state of fatty degeneration with granular exudation in the intercellular matrix. Or there may occur a hypertrophic proliferation of the connective tissue leading to induration of the structure, and in some cases to a consecutive condition of atrophy that has been described as cirrhotic. Where there is a syphilitic taint in the maternal system the granulation tissue has the features characterised as gummatous. The various processes may owe their origin to syphilitic irritation. But the simpler forms of inflammation and degeneration are also sometimes found in women without traceable syphilitic history, but who have been the subjects of chronic endometritis, or of some blood-dyscrasia. The result of them is friubility of tissue, with proclivity to hæmorrhage, or compression of the vascular sinuses, or of the stems of the villi leading to secondary changes there and total loss of function of the affected part.

Thirdly, the Apoplectic changes in the placenta present themselves under different forms, and may be of various origin. Among them have sometimes been described cases where there may not have been much or any laceration of tissue, but, in a cotyledon, the blood seems to have been detained and coagulated. It is difficult to account for this thrombotic occurrence, except on the supposition that the fotal villi in the affected sinuses have first become diseased, and acted as foreign bodies on the encircling fluid, and the normal hyperinosis of pregnancy is sometimes exaggerated to a degree that renders the blood liable to thrombosis in any space where it meets morbid structures, or is slowed in its transit. True extravasations may take place on the uterine surface of the placenta. When confined to one cotyledonary area, the blood crushes the corresponding lobule ; and if there be no recurrence, the damage is not detected till after the expulsion of the secundines, when the blood-clot will be found on the compressed cotyledon fresh, or decolourised, or undergoing further change, according to the more or less recent date of its occurrence. When the blood-escape is more extensive, or when it occurs near the placental margin, it is likely to lead on to a labour complicated by accidental hæmorrhage. The true apoplexies, however, take place into the cavernous portions of the placental lobules. In some of them the extravasations may have so distended the cavity it has produced as to have burst the parietal layer of the placenty, and become visible through the opening seen on the uterine surface after the placenta is expelled. But in most cases they are detained within a cavity, which is only exposed after an incision is made into it, either from the bulging uterine or amniotic surface. They are single or multiple. They may occur at different dates of pregnancy, and according as they are more or less recent the affected lobule is found in very varying conditions. Where the accident is of recent occurrence, the placenta is markedly thickened at the seat of extravasation, and. when the cavity is opened, the blood is found still fluid or loosely coagulated, and the placental tissues are simply compressed. Perhaps in the same placenta may be found another cotyledon, also thickened, but more dense to the feel, and in it the blood is firmly congulated and becoming decolourised, whilst the placental tissues are becoming the seat of fatty degeneration. In yet another it has begun to contract, and the placental tissues are disintegruting and shrivelling: and in another part of the placenta that has become thin and hard, the whole of the placental tissues, with the entangled bloodclot, have become transformed into a dense node of tibrous tissue, in which no further trace of chorionic or decidual elements can be discovered. It is not always easy to determine whether the extravasation is a cause or a consequence of the attendant tissue degenerations. In some of the syphilitic placentse it seems pretty 
evident that the interference with the circulation in a specially affected area may lead to hyperemia in neighbouring territories, and 80 to the tendency to congestion and extravasation there. In some cases the degenerative processes in the placental elements will render them unusually friahle, so that a degree of disturbance that in a healthy placenta will cause only a temporary congestion will in them bring about a laceration in the wide-meshed trabecular layer. But in other instances the extravasation is primary. The placentul tissues may be all healthy, and yet extravasations will take place in women who are the subjects of typhoid or other fever, or who suffer from anamia, leukæmia, or other morbid stutes of the blood. There is a notable tendency to such recurrent placental apoplexies in pregnant women with chronic Bright's disease, and the hiemorrliages occur more readily in women of relaxed fibre, in whom there is marked relaxation of the uterine walls and deficiency in the tonic rhythmical contractions characteristic of the healthy gravid uterus. The influence on the life and developnent of the fotus vary with the number of the lobules implicated, and the dates at which the accident occurs. If many lobules are simultaneously implicated, the fotus may die quickly of the sudden interference with its oxygenating organ. When the lobules are affected in succession and with some weeks of interval between the destruction of the several lobules, the fœetus may survive, but be born ill-nourished, delicate, and difficult to rear.

Diafisosis.

The conditions which we have thus been considering may never be suspected, and some of them can never be recognised when they are suspected till after the expulsion of the sanguinolent fotus and its secundines. But when such a fotus has been born, careful examination should be made of the viscera, and especially of the liver and spleen, which are apt to be distinctly enlarged and otherwise modified in syphilitic children, and of the bones to trace the osteo-chondritis syphilitica of Wegner, as well as of the placenta and umbilical cord, to find the varying forms of disease they may present. And when we have a patient giving birth to a succession of such dead children, we must watch her through her following pregnancy, observing whether there be any tendency to such special tenderness in the uterine walls as has sometime's been noted in placentitic patients, or recurrence of sensations of local uneasiness or general faintness such as have sometimes seemed to indicate the dates of the occurrence of hrmorrhagic extravasations; and, above all, to note the character of the foetal heart-beats, so as to catch in the slowing and weakening of its sounds the indications of vital depression or impending denth of the futus.

Preventive Treatuent.

When in our obstetrical practice we have a patient giving birth to a series of still-born children, our first aim is to determine whether she be the subject of any constitutional diathesis, or, where she seems to be liealthy, whether there be any such indications on the part of the fatus. In a large proportion of cases there will be syphilitic manifestations more or less distinct. In giving the proportion of 83 per cent. as the result of his own investigations, Carl Ruge is probably not far off the average mark. In such patients we may hold out the hope that with the lapse of years matters will improve. If the wife, as is commonly the case, had been previously healthy, and the husband can be persuaded to let the uterus remain at rest until in process of time the virus in him lias lessened in its intensity and the tertiary symptoms have disappeared, it may become possible for him to impregnate a healtliy orum that will develop and be carried to the full term. But it should be remembered that, even where the tertiary stage has been reached, we can give no certainty of healthy procrention to a man once constitutionally syphilitic, and the most hopeful results are to be obtained by the enforcement of anti-syphilitic treatment.

I fix attention on the marital syphilis because in at least four cases out of five it is the husband who brings this miserable endowment into the marriage contract, and because it is sentimentally cruel and scientifically stupid to make the wife the subject of our efforts to counteract the effects of the poison in her person while nothing is done to neutralise it in him who at each fresh conception is infecting her anew. Mercury in its various preparations has too often been introduced into the system of pregnant women, to the detriment of their constitution, when it might have been administered with the happiest cons suences to the husband. Only after his system has been sterilised as well as hers by the lengthened use of the protiodide or other salt of mercury in regulated doses should she be exposed to the chance of a fresh conception; and, when conception has taken place, the use of the mercurial once or twice a day in small tonic doses should be continued far into or throughout the pregnancy. The administration of iodide of potassium may occasionally accompany or succeed the mercury, and the waters of Aixles-Bains, Fms, and Kissingen have sometimes been useful, especially where there remains a tendency to uterine inflammations in a patient in whom the syphilitic taint has been otherwise counteracted.

As regards other constitutional conditions, it is equally clear that we must use the resources of our art to remedy them. The annmic patient must take iron during her pregnancy, and she will sometimes do well to take arsenic in small doses along with it. The patient with albuminuria should be dieted with milk, and in her also the use of iron is often serriceable. In such patients, as well as in those affected with cardiac difficulties, the iron may be given along with digitalis, or with strophanthus, which is an excellent substitute for digitalis in the cardiac complications of pregnancy.

Where the placental disease is traceable to chronic inflammatory processes in the uterus, care must be taken to secure complete involution after the dead child has been born, and it may be necessary, before another fertilised ovum is allowed to lodge in the uterus, to make some applications to the endometrium, or let the patient have a course of the waters of Ems, Karlsbad, Kreuznach, or Kissingen.

When we have done all that we can in the way of eliminating diathetic mischiefs, and building up the patient's system and restoring the uterus to health, we ask whether there be any means of promoting the placental functions in cases where there is reason to apprehend disease or degeneration in that organ. Perhaps various substances may prove useful in this direction, but as yet the only drug that has given quite satisfactory results is the chlorate of potass. The idea under which it was first administered, that this richly oxygenous salt would part with its oxygen to the foetal blood, and so supplement the respiratory action in the impaired conditions of the placenta, has long been given up. A dose of twenty grains passes within about twenty-four hours out of the system, and can be obtained almost in its entirety in the patient's urine. But observation has abundantly confirmed the importance of its full and continuous administration, in enabling patients with placental weakness to carry their infants on to viability or to full development. It should be given in doses of fifteen or twenty grains every six or eight hours, so that there may always be some of the salt in the circulating fluid. Its use should be begun as early in pregnancy as at the third month, and it should be continued up to the hour of the infant's birth.

Our final resource in certain cases is to induce labour after the period of viability is passed, and when a fœtus is nearing the stage of development at which its uterine predecessor perished, or when by the stethoscope we detect the gigns of impending danger. The hint is of ten given us by what is seen to take place naturally. In the cases especially of the placental apoplexies, the blood extravasation sometimes produces such a degree of separation of the membranes and placenta that uterine activity is set up. We can most safely imitate the natural process by having recourse to the use of hot vaginal douches. When the period of viability is passed, the douche may be employed with water moderately warm for short periods twice a day, with the result that the uterus will simply be stimulated to healthy tonicity of action. Then, as the period of danger approaches, the douche should be used more frequently, for greater lengths of time, and with water raised to a higher temperature $\left(110^{\circ}\right.$ to $120^{\circ} \mathrm{F}$.) If uterine action remain too long in abeyance, it may be started by the introduction of a gumelastic bougie, carried up for six, eight, or ten inches into the cavity of the uterus, between its walls and the membrane of the ovum. Introduce the bougie in such a case at bed-time and leave it there, and in the morning you may expect to be called to assist at the delivery of-happily-a living and life-like infant.

Dr. BARNes expressed his admiration of the excellence of l'rofessor Simpson's survey of the causes of intra-uterine death. He would first touch upon the relations of albuminuria. He understood the profession to say that when albuminuria was observed, the proper course was to put the subject on milk diet, which implied a trust in expectancy. Now it had occurred to him to meet in consultation, even lately, three cases of albuminuria in ad- 
vanced pregnancy ; in each case a physician of great and deserved repute for skill in kidney disease opposed his advice to induce labour; in each case the foetus was born dead, in one case the mother died. IIe believed that albuminuria was a common cause of intra-uterine death, and that it was the best practice, in the interest of mother and child, to induce labour. In regard to fatty degeneration, he wished to point out a distinction he had pointed out in his original memoirs between fatty degeneration and fatty metamorphosis. Degeneration affected living tissues, metamorphosis was a post-mortem change. Metamorphosis was seen in placenta of the mummified embryo in the case of twins, of which the fellow embryo lived to term. The apoplectic placenta was not always due to disease of mother or father, nor to any abnormal condition of maternal blood. It was in some case's i protest of Nature against pregnancy. Nature could not always tolerate pregnancy. This was especially observed in conceptions at early and late ages. In the first case the reproductive organs were imperfectly evolved; in the second case senile involution had set in. Then there were cases in which, under excessive nervous and vascular tension, exaggerated at the menstrual epochs, effusions of blood took place most readily at the wonted points that are in the uterine structures, hence apoplectic abortions. In other cases, hæmorrhages might occur from the nose, lungs, or bowels; these hæmorrhages were in some sense vicarious; they might thus avert an abortion. In regard to syphilis, he felt it was sometimes cited vaguely, and too of ten assigned as the cause of abortional disease of placenta. He would not trespass further. The subject, as handled by Professor Simpson, was so vast that it covered the whole range of gynzecology.-Dr. BYers said that l'rofessor Simpson's admirable address clearly showed that the causes of intra-uterine death were very numerous, and that in the case of recurring abortions, the problem of causation was one demanding very careful consideration. Looking at the question from the practical point of view, he thought, apart from such causes as anxmia of the mother, high temperature, nlbuminuria, etc., there were three common causes: 1, syphilis, which had a direct action on the fœtus, and was also associated with placental disease and hydramnion. The results of treatment of both parents was, he thought, most satisfactory ; 2 , endometritis ; here he had found curetting useful ; 3 , displacements. Ile wished to draw attention to the value of treatment in two sets of cases. 1. In cases of recurring deaths of the foetus towards the latter part of gestation, where there was no history of syphilis, he had found the treatment recommended by Dr. McClintock, of Dublin, of great service-namely, combining tincture of iron with the chlorate of potash, commencing the drugs some weeks before the time at which, in previous gestations, death had occurred, and continuing them on to the end of gestation. In cases of recurring abortions in the early months, where there is no syphilitic history and no evidence of local disease, Dr. Byers said he had found the ext. viburni prunifolii of considerable use-that is, in cases of "irritable uterus." Finally, he drew attention to the value of preventing constipation, which from its effect in causing pelvic congestion he thought of tengave rise to intra-uterine death. Dr. FordYce BARker (New York) drew attention to one calise of intra-uterine death, which he considered apt to be overlooked. He called it perverted maternal nutrition, a state in which the patients became increased in weight during pregnancy, and yet aborted apparently from lack of proper nutrition of the foctus. He gave details of cases where a spare diet and active exercise kept down increased body weight, and resulted in the birth of children at the full time.-Dr. Parvin said that after one speech by an American physician they would hardly care for another one, but, if they insisted, he would merely refer to abortion occurring from that condition of the uterus first describer by Gooch as irritability of that organ. There was a difference in the response given to an irritant by the uterus of one woman and that of another. Those very slight, possibly inappreciable, causes miglit, in one instance, cause miscarriage, while the fullest violence to which another might be subjected was harmless. the pregnancy going to term. Then, too, we had this difference in irritnbility illustrated in some cases in which we wished to induce premature labour. In one woman the separation of the membranes by a bougie left in the uterus twenty-four hours, or eren less, would bring on labour, while in another repeated application would be made, and it might be a week before lubour pains were fairly established. He thought it must be admitted that in some cases abortion resulted purely from the irritable condition of the uterus, there being no other obvious disease of that organ.
Whether we had any special nterine nerve-sedative might be questioned. Such virtue had been claimed for viburnum prunifolium, but the testimony was conflicting. He miglit mentiun that this remedy was first used by slave women in the southern part of the United States, and their professional attention (al.led to) it by Dr. Phares, of Mississippi.-Dr. II. P. C. Wison (Baltimore'said lie would not say anything upon the pathology of int rit-uterme death. This had been exhausted by Dr. Simpsion's paper. He would speak solely of those causes external to the uterus, within the pelvis. He referred to uterine displacements, constipation, retention of urine, and shortening of the uterine ligaments by which the uterus was prevented from resting in the pelvis as the fortus grew. Often a properly adjustenl jesary, which a.e stored a retroversion and retained it comfortably in place, winld prevent an abortion; so, also, the use of gentle cathartios every day. He had not much confidence in any medicin. us a lieventive of abortion. The first indication of an approachiner aliortion was a slight show of blood. In many instances, if the woman was kejt in bed, and giren moderate dose's of ergut, so as to produce contraction of the vessels of the uterus, the liemorrhage was checked, separation of the foctal memlirines from the wall of the uterus prevented, and the foetus saved. It should not be given in doses sufficient to produce nterine contractions.Dr. Alst LAWRENCE related two cases: in the tir:t. a woman had had six dead children at full time, and was diabetic; labour was induced. and a living child resulted. In the second, a woman had had four rifind chilelren at full time; labour was induced at the eighth month, with a living child resulting, which died one month aftermards with acute jaundice, with fatty liver, which no doult had comm:enced in utero, and was probably the cause of the death of the other infants. There was no history of syphilis.-Dr. Antul'n $\mathbb{W}$. Eirs (London) thought the subject was tuo comprelsensive to consir?tr.r it fully in detail. I'rofessor Simpson's able statement of the numerous conditions affecting the fatus in uferonly showed linv vast was the outlook, and the practitioner would clo weil to hear this in mind. In any individual case he should carefully enturnvenr to ascertain what special series of causes were influencing the gestation, and olviate them. In the early stages, doubtiess, misplacements, constipation, chronic metritis, and other local conditions had great influence. Later on, pot. chlor. and iron was of great service if all trace of syphilis could be excludi.ul: l.ut Protfessor Barker had suggested a most practical conclusion-which he (Dr. Edis) had long since acted upon. In one case, a yeoman farmer's wife, who had given birth to no less than elevell sillborn children prematurely, Dr. Edis succeeded in carrying her safely on to full time, with three living children, me-rely by a-certaining carefully her mode of life. She was a healthy, well-made womнn, but thought much more of breeding and fattening turkeys and fowls than looking after her own health. Attention to a suries of details, abstention from stimulants, and exhorting the linsl and to give the same care to his wife as he did to his bringl mares, :treceeded in accomplishing the object desired, with very litte id from medicine.-Dr. AMA ND Rov'H empliasised especially the importance of examining the urine carefully in all cases witere no other local or constitutional cause was discoverel. II hiol fulund, in quite a number of such cases, slight traces of albumen in women who had the habit of aborting, in whom allouminuria wils unsuspected. This albuminuria is sometimes due to calls de lendent upon the pregnancy, but are not very rarely due to insidious granular disease, and such cases are not unlikily to lie the cause of puerperal eclampsia, if abortion does not early occur. In two or three cases, where every organ and function sement normal in the woman, he had found granular kidney disease to exist in the husband.-The President (Dr. Jore MA WIN E) sail that no subject could more properly occupy the attention of the Section than the preventive treatment of intra-uterine d.ath, the freiner:cy of abortions being more than one-thirl that of normal living list his. The causes of abortion had been so fully consillered luring this discussion, he would not further occupy their time, wexcept to rald that he had learned, by long olistetric experience, that of all the causes of abortion by far the most frequent was the -rpliiitie taint, and the only effectual preventive treatment was the longcontinued arlministration of bichloride of mercury in minute doses, and given in tincture of bark.

Beocrsts. - The Glasgow Royal and Western infixmaries liave each been bequeathed $f_{x}(M)$ free of legacy duty by the late $\mathrm{Mr}$. James W. Greenlees, distiller, of Campbeltown. 